\title{
ANÁLISE DE IMPACTO REGULATÓRIO E PRAGMATISMO JURÍDICO: LEVANDO AS CONSEQUÊNCIAS REGULATÓRIAS A SÉRIO
}

\author{
REGULATORY IMPACT ANALYSIS AND LEGAL PRAGMATISM: TAKING \\ REGULATORY CONSEQUENCES SERIOUSLY
}

Rafael Carvalho Rezende Oliveira ${ }^{1}$

\begin{abstract}
RESUMO
O presente artigo tem por objetivo abordar a intensa relação entre a Análise de Impacto Regulatório (AIR) e o pragmatismo jurídico que enfatizam a importância das consequências da decisão pública. Após as alterações promovidas na Lei de Introdução às Normas do Direito Brasileiro (LINDB) em 2018, que enfatizaram a relevância das consequências práticas e jurídicas na decisão pública, o estudo do pragmatismo jurídico foi intensificado na doutrina. A presente pesquisa pretende demonstrar a relevância da aplicação da visão consequencialista no campo regulatório. No Direito Regulatório, a AIR tem sido considerada relevante instrumento de planejamento e de monitoramento das consequências na produção de atos normativos por parte das agências reguladoras, uma vez que possibilita maior racionalidade, transparência e eficiência ao processo decisório. O método utilizado foi qualitativo e descritivo, com a análise da legislação em vigor e da bibliografia sobre o tema do estudo. Ao final, o artigo pretende demonstrar a crescente relevância da Análise de Impacto Regulatório no ordenamento jurídico brasileiro, bem como apresentar considerações teóricas que podem contribuir para boas práticas regulatórias.
\end{abstract}

Palavras-chave: Direito Regulatório. Análise de Impacto Regulatório. Pragmatismo jurídico. Consequencialismo. LINDB.

\begin{abstract}
${ }^{1}$ Visiting Scholar pela Fordham University School of Law (NY). Doutor em Direito pela Universidade Veiga de Almeida (UVA/RJ). Mestre em Direito Constitucional pela Pontifícia Universidade Católica do Rio de Janeiro (PUC/RJ), Pós-graduado em Direito do Estado pela Universidade do Estado do Rio de Janeiro (UERJ), graduado em Direito pela PUC/RJ. Professor Titular de Direito Administrativo do IBMEC. Professor do Programa de Pósgraduação Stricto Sensu em Direito - Mestrado e Doutorado (PPGD/UVA). Procurador do Município do Rio de Janeiro. Ex-Defensor Público da União. Professor de Direito Administrativo dos cursos de pós-graduação lato sensu da fundação Getúlio Varga (FGV) e da Universidade Cândido Mendes. Professor de Direito Administrativo dos cursos preparatórios para concursos públicos (Curso FORUM e CERS) e da Escola da Magisratura do Estado do Rio de Janeiro (EMERJ). Membro do Instituto de Direito Administrativo do Estado do Rio de Janeiro (IDAERJ). Membro do Conselho editorial da Revista Colunistas de Direito do Estado. Presidente do Conselho editorial interno da Revista Brasileira de Alternative Dispute Resolution (RBADR). Membro da lista de árbitros do Centro Brasileiro de Mediação e Arbitragem (CBMA) e da Câmara de Mediação e Arbitragem Especializada (CAMES). Autor de livros e artigos jurídicos. Sócio-fundador do escritório Rafael Oliveira Advogados Associados. Advogado, árbitro e consultor jurídico. Universidade Veiga de Almeida e Centro Universitário Ibmec/RJ - $\quad$ Brasil. ORCID: http://orcid.org/0000-0002-8823-1393 Lattes: http://lattes.cnpq.br/3494213691762133 E-mail: rafaelpgm@yahoo.com.br
\end{abstract}


This article aims to address the intense relationship between Regulatory Impact Analysis (RIA) and legal pragmatism that emphasize the importance of the consequences of public decision. After the changes promoted in the Law of Introduction to the Rules of Brazilian Law (LINDB) in 2018, which emphasized the relevance of practical and legal consequences in public decision, the study of legal pragmatism was intensified in the doctrine. This research aims to demonstrate the relevance of applying the consequentialist view in the regulatory field. In Regulatory Law, RIA has been considered a relevant instrument for planning and monitoring the consequences for the production of normative acts by regulatory agencies, since it allows greater rationality, transparency and efficiency in the decision-making process. The method used was qualitative and descriptive, with the analysis of the legislation in force and the bibliography on the subject of the study. In the end, the article intends to demonstrate the increasing relevance of Regulatory Impact Analysis in the Brazilian legal system, as well as to present theoretical considerations that can contribute to good regulatory practices.

Keywords: Regulatory Law. Regulatory Impact Analysis. Legal pragmatism. Consequentialism. LINDB.

\section{INTRODUÇÃO}

Em artigo publicado em 2011, foi demonstrada a importância da difusão e da efetivação da Análise de Impacto Regulatório (AIR) como instrumento de melhoria da governança regulatória (OLIVEIRA, 2011a).

Ao final daquele trabalho, apresentamos algumas sugestões de aprimoramento da AIR no ordenamento pátrio, tais como: a) institucionalização: edição de normas legais e regulamentares que estabeleçam a obrigatoriedade da AIR para edição de determinados atos regulatórios, salvo casos excepcionais devidamente justificados; b) padronização mínima: a AIR deve observar uma padronização mínima, prevista em normas gerais, com o objetivo de garantir uniformidade às regulações, sem desmerecer as exigências específicas a serem definidas no âmbito de cada setor regulado; c) agenda regulatória: estipulação de agendas regulatórias; d) participação popular: reforço da previsão e da efetivação dos instrumentos de participação popular (audiências e consultas públicas) na formulação e no controle dos atos regulatórios, inclusive no procedimento da AIR; e) transparência: ampla divulgação dos atos necessários à implementação da AIR; e f) monitoramento e revisão: monitoramento periódico, com o objetivo de analisar a eficiência da norma regulatória.

É possível perceber, nos últimos anos, a implementação significativa de algumas das referidas sugestões, com a ampliação da utilização da AIR por agências reguladoras brasileiras e o reconhecimento da sua importância pelo ordenamento jurídico, notadamente após a 
promulgação da Lei 13.848/2019 (Lei das Agências Reguladoras) e da Lei 13.874/2019 (Lei de Liberdade Econômica).

O presente estudo pretende demonstrar que esse movimento crescente de institucionalização da AIR possui íntima ligação com o pragmatismo jurídico que foi reforçado pelas alterações promovidas na Lei de Introdução das do Direito Brasileiro (LINDB) pela Lei $13.655 / 2018$.

Ao destacar a relevância das consequências da decisão estatal, o pragmatismo jurídico abre espaço para procedimentos administrativos capazes de coletar informações necessárias à ponderação entre os custos e os benefícios envolvidos nos possíveis caminhos regulatórios em diversos setores da economia, viabilizando, em tese, a adoção de melhores decisões estatais.

A antecipação de possíveis consequências da proposta da norma regulatória por meio da realização da AIR (abordagem prospectiva ou forward-looking) e o constante monitoramento dessas consequências por meio da Avaliação de Resultado Regulatório (ARR) - uma espécie de AIR realizada após a implementação da norma (abordagem retrospectiva ou backward-looking) - são mecanismos importantes na busca da eficiência da política regulatória, como será demonstrado nos itens seguintes do presente artigo.

\section{PRAGMATISMO JURÍDICO E A LEI DE INTRODUÇÃO ÀS NORMAS DO DIREITO BRASILEIRO (LINDB)}

O pragmatismo nasceu nos EUA, em meados do século XIX, com as obras de Charles Sander Peirce e William James, criadores do denominado Clube Metafísico Metaphysical Club (MENAND, 2001). ${ }^{2}$ A denominação do referido clube foi escolhida de forma irônica, pois o objetivo do grupo era criticar a metafísica tradicional e seu pensamento abstrato desconectado da prática.

O pragmatismo não possui concepção unívoca, mas há relativo consenso de que as suas características básicas são (POGREBINSCHI, 2005, p. 27-62; ARGUELHES e LEAL, p. 176): $:^{3}$ a) antifundacionalismo: rejeita a existência de entidades metafísicas ou conceitos

\footnotetext{
${ }^{2}$ Os outros integrantes do Clube Metafísico foram Oliver Wendell Holmes, Nicholas St. John Green, Joseph Bangs Warner, John Fiske, Francis Ellingwood Abbot e Chauncey Wright. É possível mencionar, ainda, outros expoentes do pragmatismo, tais como John Dewey, Richard Rorty, Oliver Wendell Holmes, Benjamin Cardozo e Richard Posner.

${ }^{3}$ Margarida Lacombe Camargo (2009, p. 368-369) acrescenta ao rol outras duas características: instrumentalismo (o Direito é encarado como instrumento de orientação da conduta social) e a interdisciplinariedade (os efeitos da ação devem ser ponderados por conhecimentos de outras áreas do conhecimento).
} 
abstratos, estáticos e definitivos no Direito ${ }^{4}$ b) contextualismo: a interpretação jurídica é norteada por questões práticas e o Direito é visto como prática social $;{ }^{5}$ e c) consequencialismo: as decisões devem ser tomadas a partir de suas consequências práticas (olhar para o futuro e não para o passado). ${ }^{6}$

O pragmatismo jurídico pode e deve ser considerado instrumento idôneo no processo de interpretação do ordenamento jurídico pátrio. ${ }^{7}$ Nesse ponto, José Vicente Santos de Mendonça (2014, p. 115-122) propõe o denominado "modelo cauteloso de pragmatismo jurídico", adaptado à tradição, jurisprudencial e doutrinária, brasileira, cuja aplicação seria pautada pelos seguintes standards: a) o "princípio" do pragmatismo jurídico incide no final do iter interpretativo para descartar ou reforçar as possibilidades interpretativas tradicionais; b) a incidência ocorre dentro da extensão de significados linguísticos possíveis permitidos pelo texto normativo; c) as consequências da decisão devem ser compatíveis com a Constituição; d) as consequências certas ou prováveis devem ser consideradas, mas não as plausíveis; e) igualmente, as consequências imediatas e futuras são consideradas na decisão, mas não as remotamente futuras; f) a decisão considera as consequências fáticas com razoável base empírica; g) o pragmatismo não considera consequências fundacionais e, portanto, é antifundacionalista; e h) há prioridade nas consequências contextuais.

Não obstante o pragmatismo tenha surgido no sistema da Common Law, sua utilização é possível no sistema da Civil Law, com as devidas adaptações, especialmente pela crescente aproximação desses dois sistemas jurídicos (DAVID, 1978, p. 48; OLIVEIRA, 2018, p. 29-33). O pragmatismo se amolda ao ordenamento jurídico pátrio, em virtude, especialmente, do pluralismo que caracteriza a sociedade brasileira. Os diversos interesses consagrados e protegidos no texto constitucional denotam a impossibilidade de existência de preferências normativas absolutas, abrindo caminho para ponderação no caso concreto.

\footnotetext{
${ }^{4}$ Richard Posner (2005, p. 5-6), expoente do pragmatismo jurídico na atualidade, rejeita a possibilidade de estabelecer a verdade a partir de proposições metafisicas a priori, atribuindo-se apenas valor psicológico ou estético a metafisica.

${ }^{5}$ Ha uma evidente semelhança, nesse ponto, entre o pragmatismo, a tópica de Theodor Viehweg, a (nova) retórica de Chaim Perelman e as concepções argumentativas em geral, que valorizam o contexto no processo de interpretação e de aplicação do Direito. Da mesma forma, o pragmatismo apresenta pontos de contato com o realismo jurídico, o movimento do "direito livre", Law \& Society, Law \& Economics, entre outras escolas de pensamento.

${ }^{6}$ Sobre a interpretação consequencialista do Direito administrativo, vide: ARAGÃO, 2009 e OLIVEIRA, 2011 b. ${ }^{7}$ Apesar de não haver uniformidade em sua conceituação, o pragmatismo jurídico e concebido por alguns autores como a aplicação da tradição filosófica do pragmatismo a questão da interpretação jurídica. (EISENBERG, 2006, p. 656).
} 
Ao refutar dogmas, prestigiar o contexto e ponderar as consequências, o pragmatismo passa a ser considerado importante instrumento de interpretação e de aplicação do direito em ordenamentos jurídicos plurais e democráticos.

A ênfase nas consequências sociais e econômicas da interpretação enseja a crescente correspondência entre a norma e a realidade, afastando promessas legislativas utópicas que desconsideram o contexto econômico e social em que serão aplicadas. A ausência de efetividade do ordenamento jurídico pode ser representada pela distância entre o idealismo (ou fanatismo) legislativo e a realidade. ${ }^{8}$

Ao lado de alguns exemplos esporádicos na jurisprudência, ${ }^{9}$ o pragmatismo jurídico ganhou destaque especial com a promulgação da Lei 13.655/2018 que inseriu os arts. 20 a 30 na Lei de Introdução às Normas do Direito Brasileiro (LINDB).

Em diversas passagens, as novas disposições da LINDB revelam a preocupação com a interpretação pautada pelo antifundacionalismo, contextualismo e consequencialismo na atuação dos órgãos estatais, notadamente na tarefa do controle.

Assim, por exemplo, o art. 20 da LINDB demonstra nítida preocupação antifundacionalista e consequencialista ao estabelecer a impossibilidade de decisões, nas esferas administrativa, controladora e judicial, com base em valores jurídicos abstratos sem que sejam consideradas as consequências práticas da decisão. Em seu parágrafo único, o art. 20 da LINDB reforça a importância da motivação das decisões estatais que devem demonstrar a necessidade e a adequação da decisão, inclusive em face das possíveis alternativas.

De forma semelhante, o Código de Processo Civil de 2015, em seu art. 489, § $1^{\circ}$, considera não fundamentada a sentença que, por exemplo: a) indica ou reproduz ato normativo, sem explicar sua relação com a causa ou a questão decidida; b) utiliza conceitos jurídicos indeterminados, sem explicar o motivo concreto de sua incidência no caso; c) invoca motivos que se prestariam a justificar qualquer outra decisão; etc. Aliás, a exigência de motivação qualificada e contextualizada da sentença judicial também deve ser observada nas decisões exaradas nos processos administrativos, seja por força do art. 15 do $\mathrm{CPC}$, que determina a

\footnotetext{
${ }^{8}$ Nesse sentido, é pertinente a observação de Claudio Pereira Souza Neto (2006, p. 87-88) quando afirma que o consequencialismo "serve apenas para autorizar a ponderação das conseqüências, mas tais conseqüências podem ser valoradas de acordo com princípios que compõem o núcleo normativo da Constituição Federal de 1988."

9 Mencione-se, por exemplo, uma célebre hipótese de "inconstitucionalidade progressiva" (ou "lei ainda constitucional". O STF admitiu a subsistência temporária da legitimação do MP para propositura da ação civil ex delicto, prevista no art. 68 do CPP, nos estados da federação em que não houver Defensoria Pública regularmente instituída. A não recepção da norma em comento geraria como consequência prática a ausência de assistência jurídica e integral aos necessitados, o que afrontaria o art. $5^{\circ}$, LXXIV, da CRFB. STF, RE 135.328/SP, Rel. Min. Marco Aurélio, Tribunal Pleno. DJ 29/04/01, p. 137.
} 
aplicação supletiva e subsidiária das normas processuais civis aos processos administrativos, seja em razão das disposições especiais previstas nos arts. $2^{\circ}$ e 50 da Lei 9.784/1999, que exigem motivação explícita, clara e congruente dos atos administrativos.

A importância das consequências da decisão estatal também pode ser retirada do art. 21 da LINDB que exige a indicação expressa das consequências jurídicas e administrativas da “decisão que, nas esferas administrativa, controladora ou judicial, decretar a invalidação de ato, contrato, ajuste, processo ou norma administrativa".

Mencione-se, ainda, a relevância do contextualismo, outra característica do pragmatismo jurídico, no art. 22 da LINDB que dispõe sobre a necessidade de considerar, na interpretação das normas sobre gestão pública, "os obstáculos e as dificuldades reais do gestor e as exigências das políticas públicas a seu cargo, sem prejuízo dos direitos dos administrados".

As normas da LINDB destacadas acima devem ser aplicadas às esferas administrativa, controladora e judicial, sendo certo que a esfera administrativa compreende os órgãos e as entidades da Administração Pública direta e indireta, incluídas, naturalmente, as agências reguladoras, que possuem natureza jurídica de autarquias com regime jurídico especial.

No Direito Regulatório, a implementação dos ideais pragmatistas consagrados na LINDB, especialmente o consequencialismo na interpretação e na aplicação das normas jurídicas, são efetivados com maior intensidade por meio da institucionalização da AIR na elaboração e na revisão dos atos normativos regulatórios.

Ao identificar de maneira clara e fundamentada o contexto, bem como as consequências atuais e futuras da regulação, a AIR consubstancia instrumento decisivo no atendimento da eficiência administrativa no cenário de virada pragmatista do Direito Público brasileiro contemporâneo (MENDONÇA, 2010, p. 30).

\section{ANÁLISE DE IMPACTO REGULATÓRIO (AIR), PRAGMATISMO JURÍDICO E A IMPORTÂNCIA DAS CONSEQUÊNCIAS REGULATÓRIAS}


Entre os diversos fundamentos da AIR, merece destaque o pragmatismo jurídico, cujo debate tem sido ampliado no Brasil nos últimos anos no campo da elaboração e do controle dos atos estatais. $^{10}$

A busca da qualidade regulatória representa um dever estatal que decorre do princípio da eficiência consagrado no art. 37, caput, da CRFB, relaciona-se com a concretização das finalidades estatais elencadas pelo texto constitucional e, por consequência, com a satisfação das necessidades da população.

No âmbito da "Administração de Resultados" (SORRENTINO, 2003; SPASIANO, 2003; MOREIRA NETO, 2008), a efetivação do princípio da eficiência passa por três estágios: a) planejamento: planos de ação, orçamento e prioridades, com destaque para participação da população por meio de audiências e consultas públicas; b) execução: medidas concretas para satisfação dos resultados previamente delimitados; e c) controle: os órgãos controladores não devem se restringir à legalidade formal na análise da juridicidade da ação administrativa, devendo levar em consideração os demais princípios e o alcance dos resultados esperados.

A preocupação com os resultados da ação administrativa demonstra a íntima ligação entre o princípio da eficiência e o pragmatismo.

A institucionalização da denominada Análise de Impacto Regulatório (AIR) no direito comparado tem sido justificada pela necessidade de implementação da governança regulatória, com a diminuição das assimetrias informacionais e racionalização da atividade estatal. ${ }^{11}$

Não obstante o caráter polissêmico da expressão, a "governança" pode ser compreendida como o conjunto de mecanismos e de procedimentos que garantem maior participação da sociedade na formulação das decisões estatais, que devem ser pautadas pela eficiência e submetidas a controle e social.

No campo específico da regulação, a efetivação da governança regulatória encontra-se apoiada em três pilares (OLIVEIRA, 2015, p. 259): a) legitimidade: consagração de instrumentos participatórios na elaboração das decisões do regulador; b) eficiência: ênfase no planejamento e na busca dos resultados esperados; e c) accountability: reforço e racionalidade do controle, social e institucional, por parte dos reguladores.

Os referidos pilares da governança são encontrados na AIR, considerada como “processo de identificação sistemática e avaliação dos efeitos esperados das propostas

\footnotetext{
${ }^{10}$ Como destacado em obra específica sobre o tema, os fundamentos da AIR relacionam-se ao princípio da eficiência, ao pluralismo e à legitimidade democrática (OLIVEIRA, 2015, p. 261-269).

${ }^{11}$ No Direito comparado, a AIR e uma ferramenta utilizada de maneira crescente para avaliação das políticas regulatórias, especialmente no âmbito dos países integrantes da OCDE (JACOBS, 1997, p. 13-30).
} 
regulatórias, por meio de método analítico consistente, tal como análise de custo/benefício" (OECD, 2008).

No contexto de governança regulatória, as agências reguladoras desempenham papel de destaque, especialmente em razão da autonomia institucional.

No entanto, não bastam as estruturas, organizacional e administrativa, para garantir a efetivação dos objetivos da governança regulatória; revela-se necessária também a instrumentalização de boas práticas regulatórias por meio de procedimentos que garantam maior eficiência, participação e transparência às decisões regulatórias, tal como ocorre com a AIR.

Nesse contexto, a Análise de Impacto Regulatório - AIR tem como objetivo principal dotar a agência reguladora de ferramentas que permitam a tomada de decisão criteriosa e informada, por meio da sua racionalização.

O processo de AIR permite, de um lado, o recebimento de subsídios necessários para a construção do conhecimento sobre dada matéria e, de outro, torna o processo decisório mais transparente e controlável, na medida em que força a Administração a expor os motivos que tornam as soluções propostas mais adequadas que as demais alternativas disponíveis.

O processo administrativo regulatório, como sede de diálogo entre a Administração, o mercado e a sociedade civil, permite a melhor composição dos diversos interesses públicos e privados, eventualmente conflitantes, superando, na medida do possível, o caráter unilateral da atividade administrativa.

A instituição de "canais participatórios" serve para a solução negociada dos conflitos de interesses, permitindo melhor ponderação pelas autoridades regulatórias dos interesses dos particulares (usuários e consumidores), identificando, com maior precisão, os problemas e as possíveis consequências da futura decisão (OLIVEIRA, 2015, p. 269).

Ressalte-se que a AIR não funciona apenas como instrumento para definição da intensidade e/ou da qualidade da regulação estatal.

Em verdade, a própria decisão quanto à necessidade de instituição da regulação é discutida na AIR. Durante o processo, as alternativas à regulação direta (ex.: subsídios, disponibilização de informação ao público, instituição de taxas, autorregulação etc.) devem ser ponderadas para eleger a melhor decisão para o setor.

Ademais, a AIR não deve ser pautada exclusivamente por critérios econômicos, especialmente pelo fato de que a Administração tem o dever de considerar outros aspectos igualmente fundamentais: qualidade do serviço ou do bem, consequências ambientais, 
universalização do serviço para o maior número possível de pessoas etc. A eficiência da AIR, portanto, depende da efetivação dos resultados (econômicos, sociais, ambientais etc.) esperados pela sociedade e impostos pelo ordenamento jurídico.

Com marco inicial no Decreto 4.176/2002 (SALGADO, 2010), que estabelecia normas e diretrizes para a elaboração, a redação, a alteração, a consolidação e o encaminhamento ao Presidente da República de projetos de atos normativos de competência dos órgãos executivos federais, posteriormente revogado pelo Decreto 9.191/2017, a AIR foi intensificada por meio do "Programa de Fortalecimento da Capacidade Institucional para Gestão em Regulação (PROREG)", instituído pelo Decreto 6.062/2007, com o objetivo de fortalecer os mecanismos institucionais para gestão regulatória, com ênfase na autonomia decisória das agências reguladoras e no aprimoramento do controle institucional e social. ${ }^{12}$

O Comitê Interministerial de Governança (CIG), instituído pelo Decreto 9.203/2017 (Decreto de Governança), aprovou o documento com o título "Diretrizes gerais e guia orientativo para elaboração de Análise de Impacto Regulatório - AIR", com o objetivo de orientar a elaboração e a aplicação da AIR na Administração Pública federal (CASA CIVIL DA PRESIDÊNCIA DA REPÚBLICA, 2018). O referido documento é pautado por dois princípios básicos: a) necessidade de implementar a AIR no estágio inicial de elaboração das normas regulatórias; e b) importância do fomento à integração de mecanismos de participação social durante a AIR.

A Lei 13.848, de 25 de junho de 2019 (Lei das Agências Reguladoras), que dispõe sobre a gestão, a organização, o processo decisório e o controle social das agências reguladoras federais, trouxe importantes comandos sobre a tomada de decisões no âmbito das agências. O art. $6^{\circ}$ da Lei 13.848/2019 dispõe:

Art. $6^{\circ}$. A adoção e as propostas de alteração de atos normativos de interesse geral dos agentes econômicos, consumidores ou usuários dos serviços prestados serão, nos termos de regulamento, precedidas da realização de Análise de Impacto Regulatório (AIR), que conterá informações e dados sobre os possíveis efeitos do ato normativo.

De acordo com o referido diploma legal, o regulamento deverá tratar do conteúdo e da metodologia da AIR, dos quesitos mínimos a serem objeto de exame, bem como indicará os casos em que será obrigatória sua realização e as hipóteses de sua dispensa, cabendo ao

\footnotetext{
${ }^{12} \mathrm{O}$ art. $2^{\circ}$ do Decreto n. 6.062/2007 elenca os objetivos específicos do PRO-REG, sendo possível destacar a necessidade de aprimoramento da "capacidade de formulação e análise de políticas públicas em setores regulados", a "melhoria da coordenação e do alinhamento estratégico entre políticas setoriais e processo regulatório", o "fortalecimento da autonomia, transparência e desempenho das agências reguladoras", bem como o desenvolvimento e aperfeiçoamento de mecanismos para o exercício do controle social do processo regulatório.
} 
regimento interno de cada agência dispor sobre a sua operacionalização (art. $6^{\circ}, \S \S 1^{\circ}$ e $2^{\circ}$, da Lei $13.848 / 2019){ }^{13}$

As decisões regulatórias das agências possuem caráter colegiado, motivo pelo qual o conselho diretor ou a diretoria colegiada deverá analisar o relatório de AIR e se manifestar sobre a adequação da proposta de ato normativo aos objetivos pretendidos, indicando se os impactos estimados recomendam sua adoção, e, quando for o caso, quais os complementos necessários (arts. $6^{\circ}, \S 3^{\circ}$, e $7^{\circ}$, da Lei 13.848/2019).

De acordo com o art. $2^{\circ}$, caput, da Lei 13.848/2019, o referido diploma legal é aplicável às agências reguladoras federais, a saber: Agência Nacional de Energia Elétrica (ANEEL); Agência Nacional do Petróleo, Gás Natural e Biocombustíveis (ANP); Agência Nacional de Telecomunicações (ANATEL); Agência Nacional de Vigilância Sanitária (Anvisa); Agência Nacional de Saúde Suplementar (ANS); Agência Nacional de Águas (ANA); Agência Nacional de Transportes Aquaviários (ANTAQ); Agência Nacional de Transportes Terrestres (ANTT); Agência Nacional do Cinema (ANCINE); Agência Nacional de Aviação Civil (ANAC); e Agência Nacional de Mineração (ANM). O parágrafo único do art. $2^{\circ}$ da Lei 13.848/2019, por sua vez, determina a sua incidência, ainda, às autarquias especiais caracterizadas como agências reguladoras e criadas a partir vigência da Lei em comento.

A ANVISA tem se destacado na realização pioneira da AIR. A agência instituiu o Programa de Melhoria do Processo de Regulamentação da Anvisa (PMR), por meio da Portaria 422/2008, com o objetivo de aperfeiçoar e modernizar as práticas regulatórias da agência, garantindo maior previsibilidade, legitimidade, transparência e estabilidade ao processo regulatório. A referida Portaria foi revogada pela Portaria 1.741/2018 que define a AIR como "processo sistemático de análise, baseado em evidências, que busca avaliar, a partir da definição de um problema regulatório, os possíveis impactos das opções de ação disponíveis para o alcance dos objetivos pretendidos, tendo como finalidade orientar e subsidiar a tomada de decisão" (art. $2^{\circ}$, III).

Em seguida, a referida Portaria conceitua a Avaliação de Resultado Regulatório (ARR) como "avaliação do desempenho do ato normativo adotado ou alterado, considerando o atingimento dos objetivos e resultados originalmente pretendidos, bem como os demais impactos observados sobre o mercado e a sociedade, em decorrência de sua implementação (art. $2^{\circ}$, IV).

\footnotetext{
${ }^{13}$ Nos casos dispensa de AIR, deverá ser disponibilizada, no mínimo, nota técnica ou documento equivalente que tenha fundamentado a proposta de decisão (art. $6^{\circ}, \S 5^{\circ}$, da Lei 13.848/2019).
} 
A realização da AIR na ANVISA é obrigatória, em princípio, para propostas de adoção e de alteração de atos normativos de interesse (art. 10, parágrafo único, da Portaria 1.741/2018). Contudo, a AIR não se aplica aos atos normativos que tem por objeto (art. 11 da Portaria 1.741/2018): a) a retificação de erro material de sintaxe, ortografia, pontuação, tipográficos e de numeração de normas previamente publicadas; b) a atualização de dispositivos obsoletos ou revogar atos normativos, desde que não haja alteração de mérito; e c) a consolidação de outras normas sobre determinada matéria, desde que não haja alteração de mérito.

É possível a dispensa, excepcional e justificada, da AIR nos seguintes casos (art. 12 da Portaria 1.741/2018): a) necessidade de enfrentamento de problemas de alto grau de urgência e gravidade, caracterizados por situações de iminente risco à saúde ou por circunstâncias de caso fortuito ou força maior que possam causar prejuízo ou dano de difícil reparação, e que impliquem a necessidade de atuação imediata da Agência; b) revisões de atos normativos que visem exclusivamente à simplificação administrativa, desde que não haja alteração de mérito; e c) atos normativos que possuam notório baixo impacto.

Em qualquer caso de dispensa de AIR, exige-se a elaboração de documento com pelo menos a descrição do problema regulatório que se pretende solucionar, dos objetivos que se pretende alcançar e da estratégia de implementação e monitoramento, além da devida fundamentação que motive a dispensa (art. 12, parágrafo único, da Portaria 1.741/2018).

Mencione-se, ainda, a ANEEL que estabelece a obrigação de realização, em regra, da AIR antes da edição de qualquer ato normativo. A obrigatoriedade da utilização do procedimento foi instituída pela Resolução Normativa de 540/2013, posteriormente revogada pela Resolução Normativa 798/2017, que aprimorou a Norma de Organização ANEEL 40/2013, com o intuito de aprimorar a formação da racionalidade decisória por meio da AIR.

A preocupação não se limita à elaboração da norma regulatória, mas se relaciona também, ao monitoramento dos resultados alcançados. De acordo com a Norma de Organização ANEEL 40/2013, alterada pela Resolução Normativa no 798/2017, a Análise de Impacto Regulatório (AIR) "é o processo sistemático de análise baseado em evidências que busca avaliar, a partir da definição de um problema regulatório, os possíveis impactos das alternativas de ação disponíveis para o alcance dos objetivos pretendidos, tendo como finalidade orientar e subsidiar a tomada de decisão" (art. $\left.2^{\circ}, \mathrm{I}\right)$.

Por outro lado, a Avaliação de Resultado Regulatório (ARR) “é um instrumento de avaliação do desempenho do ato normativo adotado ou alterado, considerando o atingimento dos objetivos e resultados pretendidos, bem como demais impactos observados sobre o mercado 
e a sociedade, em decorrência de sua implementação (art. $2^{\circ}$, II, da Norma de Organização ANEEL 40/2013, alterada pela Resolução Normativa nº 798/2017).

Verifica-se que diversas agências reguladoras federais editaram atos normativos com o objetivo de implementar a AIR, abrindo-se o caminho para disseminação e efetivação do instituto. $^{14}$

A relevância da AIR foi confirmada com a promulgação da Lei 13.874, de 20 de setembro de 2019 (Lei da Liberdade Econômica), que institui a Declaração de Direitos de Liberdade Econômica e estabelece garantias de livre mercado. Em seu art. $5^{\circ}$, o diploma legal estabelece:

Art. $5^{\circ}$. As propostas de edição e de alteração de atos normativos de interesse geral de agentes econômicos ou de usuários dos serviços prestados, editadas por órgão ou entidade da administração pública federal, incluídas as autarquias e as fundações públicas, serão precedidas da realização de análise de impacto regulatório, que conterá informações e dados sobre os possíveis efeitos do ato normativo para verificar a razoabilidade do seu impacto econômico.

Parágrafo único. Regulamento disporá sobre a data de início da exigência de que trata o caput deste artigo e sobre o conteúdo, a metodologia da análise de impacto regulatório, os quesitos mínimos a serem objeto de exame, as hipóteses em que será obrigatória sua realização e as hipóteses em que poderá ser dispensada.

Com o objetivo de regulamentar a AIR prevista no art. $6^{\circ}$ da Lei $13.848 / 2019$ e no art. $5^{\circ}$ da Lei 13.874/2019, foi editado o Decreto 10.411, de 30 de junho de 2020.

Conforme destacado pelo art. $1^{\circ}, \S 1^{\circ}$, do Decreto, as suas disposições devem ser observadas pelos órgãos e entidades da Administração Pública federal direta, autárquica e fundacional, quando da proposição de atos normativos de interesse geral de agentes econômicos ou de usuários dos serviços prestados.

Contudo, as suas normas não se aplicam às propostas de edição de decreto ou aos atos normativos a serem submetidos ao Congresso Nacional (art. $1^{\circ}, \S 3^{\circ}$ ).

Trata-se de expressão que confirma a famosa frase "faça o que eu digo, mas não faça o que eu faço". A exigência de AIR não deveria ser afastada da própria elaboração de decretos e outros atos normativos. Independentemente da origem da norma infralegal e do seu alcance, a realização da AIR, como já demonstrado, reforça a qualidade da norma elaborada a partir de um processo transparente e controlável.

\footnotetext{
${ }^{14}$ Além da ANVISA e da ANEEL, podem ser mencionados outros exemplos, tais como: ANATEL (art. 62, parágrafo único, do Regimento Interno - Resolução 612/2013 - e arts. 14 a 17 da Portaria 927/2015), ANA (art. $7^{\circ}$, VII, Regimento Interno aprovado pela Resolução 76/2019 e arts. 12 e 13 da Resolução 86/2018), ANTT (art. 106, XII, do Regimento Interno da ANTT, aprovado pela Resolução 5.810/2018) etc.
} 
De acordo com o art. $3^{\circ}, \S 2^{\circ}$, do Decreto 10.411/2020, a exigência de AIR também não se aplica nos seguintes atos normativos: a) de natureza administrativa, cujos efeitos sejam restritos ao âmbito interno do órgão ou da entidade; b) de efeitos concretos, destinados a disciplinar situação específica, cujos destinatários sejam individualizados; c) que disponham sobre execução orçamentária e financeira; d) que disponham estritamente sobre política cambial e monetária; e) que disponham sobre segurança nacional; e f) que visem a consolidar outras normas sobre matérias específicas, sem alteração de mérito.

Ademais, o art. $4^{\circ}$ do Decreto 10.411/2020 autoriza a dispensa de realização da AIR nas seguintes hipóteses: a) urgência; ${ }^{15}$ b) ato normativo destinado a disciplinar direitos ou obrigações definidos em norma hierarquicamente superior que não permita, técnica ou juridicamente, diferentes alternativas regulatórias; c) ato normativo considerado de baixo impacto; ${ }^{16}$ d) ato normativo que vise à atualização ou à revogação de normas consideradas obsoletas, sem alteração de mérito; e) ato normativo que vise a preservar liquidez, solvência ou higidez: e.1) dos mercados de seguro, de resseguro, de capitalização e de previdência complementar; e.2) dos mercados financeiros, de capitais e de câmbio; ou e.3) dos sistemas de pagamentos; f) ato normativo que vise a manter a convergência a padrões internacionais; g) ato normativo que reduza exigências, obrigações, restrições, requerimentos ou especificações com o objetivo de diminuir os custos regulatórios; e h) ato normativo que revise normas desatualizadas para adequá-las ao desenvolvimento tecnológico consolidado internacionalmente, nos termos do disposto no Decreto 10.229/2020.

Nos casos de dispensa de AIR, será elaborada nota técnica ou documento equivalente que fundamente a proposta de edição ou de alteração do ato normativo (art. $4^{\circ}, \S 1^{\circ}$, do Decreto $10.411 / 2020)$.

A conclusão da AIR será efetivada por meio de relatório que contenha (art. $6^{\circ}$ do Decreto 10.411/2020): a) sumário executivo objetivo e conciso, que deverá empregar linguagem simples e acessível ao público em geral; b) identificação do problema regulatório que se pretende solucionar, com a apresentação de suas causas e sua extensão; c) identificação dos agentes econômicos, dos usuários dos serviços prestados e dos demais afetados pelo problema

\footnotetext{
${ }^{15}$ A hipótese de dispensa de AIR nos casos de urgência não afasta a necessidade de nota técnica ou o documento equivalente que deverá, obrigatoriamente, identificar o problema regulatório que se pretende solucionar e os objetivos que se pretende alcançar, de modo a subsidiar a elaboração da ARR (art. $4^{\circ}, \S 2^{\circ}$, do Decreto 10.411/2020).

${ }^{16}$ Considera-se ato normativo de baixo impacto aquele que: a) não provoque aumento expressivo de custos para os agentes econômicos ou para os usuários dos serviços prestados; b) não provoque aumento expressivo de despesa orçamentária ou financeira; e c) não repercuta de forma substancial nas políticas públicas de saúde, de segurança, ambientais, econômicas ou sociais; (art. $2^{\circ}$, II, do Decreto 10.411/2020).
} 
regulatório identificado; d) identificação da fundamentação legal que ampara a ação do órgão ou da entidade quanto ao problema regulatório identificado; e) definição dos objetivos a serem alcançados; f) descrição das alternativas possíveis ao enfrentamento do problema regulatório identificado, consideradas as opções de não ação, de soluções normativas e de, sempre que possível, soluções não normativas; g) exposição dos possíveis impactos das alternativas identificadas, inclusive quanto aos seus custos regulatórios; h) considerações referentes às informações e às manifestações recebidas para a AIR em eventuais processos de participação social ou de outros processos de recebimento de subsídios de interessados na matéria em análise; i) mapeamento da experiência internacional quanto às medidas adotadas para a resolução do problema regulatório identificado; j) identificação e definição dos efeitos e riscos decorrentes da edição, da alteração ou da revogação do ato normativo; k) comparação das alternativas consideradas para a resolução do problema regulatório identificado, acompanhada de análise fundamentada que contenha a metodologia específica escolhida para o caso concreto e a alternativa ou a combinação de alternativas sugerida, considerada mais adequada à resolução do problema regulatório e ao alcance dos objetivos pretendidos; e 1) descrição da estratégia para implementação da alternativa sugerida, acompanhada das formas de monitoramento e de avaliação a serem adotadas e, quando couber, avaliação quanto à necessidade de alteração ou de revogação de normas vigentes.

$\mathrm{O}$ art. $7^{\circ}$ do Decreto 10.411/2020 indica, de forma exemplificativa, as seguintes metodologias que poderão ser utilizadas na elaboração da AIR, cuja escolha deverá ser justificada: a) análise multicritério; b) análise de custo-benefício; c) análise de custoefetividade; d) análise de custo; e) análise de risco; ou f) análise risco-risco.

Os arts. $8^{\circ}$ a 11 do Decreto 10.411/2020 tratam da participação social no procedimento da AIR, com a previsão de realização, em princípio, facultativa, de consulta pública. Em nossa opinião, a lógica deveria ser inversa, com a previsão de realização obrigatória de consulta pública, salvo situações excepcionais devidamente justificadas.

Verifica-se a preocupação com o monitoramento dos resultados alcançados pelos atos normativos. Segundo o art. $2^{\circ}$ do Decreto 10.411/2020, a Avaliação de Resultado Regulatório (ARR) é a "verificação dos efeitos decorrentes da edição de ato normativo, considerados o alcance dos objetivos originalmente pretendidos e os demais impactos observados sobre o mercado e a sociedade, em decorrência de sua implementação".

A ARR poderá ter caráter temático e ser realizada apenas quanto a partes específicas de um ou mais atos normativos, cabendo às entidades responsáveis a instituição de uma agenda de 
ARR, com a inclusão de, no mínimo, um ato normativo de interesse geral de agentes econômicos ou de usuários dos serviços prestados de seu estoque regulatório (art. $13, \S \S 1^{\circ} \mathrm{e}$ $2^{\circ}$ do Decreto 10.411/2020).

Não obstante os avanços na regulamentação da AIR, o Decreto 10.411/2020, em seu art. 21, acaba por retirar a força do próprio ato regulamentar e da AIR, abrindo caminho para ausência de sua implementação. Isso porque o descumprimento dos comandos consagrados no referido Decreto "não constitui escusa válida para o descumprimento da norma editada e nem acarreta a invalidade da norma editada". Aqui, o Decreto perdeu a oportunidade de avançar na exigência de qualificação da motivação dos atos normativos como condição para sua validade.

Apresentas as características e o regime jurídico da AIR, verifica-se que o instituto constitui importante ferramenta na formulação, execução e controle das políticas regulatórias, especialmente por efetivar os ideais da eficiência, do pluralismo e da legitimidade democrática.

É possível perceber que o debate tradicional relacionado ao papel do Estado Regulador focava a intensidade, maior ou menor, da regulação estatal a partir de ideologias opostas que confrontavam a regulação e a abstenção, como o Bem e o Mal. O pêndulo da intervenção regulatória oscila entre a maior (Escola do Interesse Público) e a menor (Escola de Chicago) intervenção estatal na economia. ${ }^{17}$

Constata-se, no entanto, uma virada importante nesse debate, com a substituição da intensidade pela qualidade da regulação (Better Regulation). O ponto central da discussão atual é a efetivação da melhor regulação (WEATHERILL, 2007, p. 1-17). ${ }^{18}$

\section{CONCLUSÃO}

Conforme demonstrado ao longo do artigo, os ideais do pragmatismo jurídico têm sido intensificados nos últimos anos no ordenamento jurídico pátrio, especialmente a partir das alterações implementadas na LINDB pela Lei 13.655/2018.

\footnotetext{
${ }^{17}$ De forma resumida (OLIVEIRA, 2015, p. 139-140), enquanto a Escola do Interesse Público: propõe a intensificação da regulação deve ser intensificada para satisfação do interesse público ou dobem comum, a Escola de Chicago (econômica ou neoclássica) propõe uma menor intervenção (ou abstenção) estatal na ordem econômica que seria justificada para corrigir as denominadas "falhas de mercado" (monopólio e poder de mercado; "bens coletivos"; e assimetrias de informações).

${ }^{18}$ Nesse contexto, Susan Rose-Ackerman (1992, p. 187) propõe uma nova agenda pública para reformar e não para desmantelar o Estado regulador, buscando melhorar a responsabilidade dos agentes políticos e os desenhos dos programas públicos.
} 
Nesse contexto, a decisão estatal nas esferas administrativa, controladora e judicial deve levar em consideração as respectivas consequências práticas, jurídicas e administrativas, o que abrange o papel do Estado na ordem econômica.

A exigência de planejamento, com o incremento racional e informacional sobre os possíveis impactos da proposta da norma regulatória, justifica a realização da AIR para permitir que os agentes reguladores avaliem os custos e os benefícios das opções regulatórias no respectivo setor econômico, garantindo maior eficiência estatal.

A preocupação consequencialista, típica do pragmatismo jurídico, deve ser levada a sério na atuação das agências reguladoras, o que justifica a crescente institucionalização da AIR por meio de normas internas das próprias agências, especialmente a partir das exigências contidas na Lei 13.848/2019 (Lei das Agências Reguladoras) e na Lei 13.874/2019 (Lei da Liberdade Econômica).

\section{REFERÊNCIAS}

ARAGÃO, Alexandre Santos de. Interpretação consequencialista e análise econômica do Direito público a luz dos princípios constitucionais da eficiência e economicidade.

SARMENTO, Daniel (org.). Vinte anos da Constituição Federal de 1988. Rio de Janeiro: Lumen Juris, 2009.

ARGUELHES, Diego Werneck; LEAL, Fernando. Pragmatismo como [meta] teoria normativa da decisão judicial: caracterização, estratégias e implicações. SARMENTO, Daniel (org.). Filosofia e teoria constitucional contemporânea. Rio de Janeiro: Lumen Juris, 2009.

CAMARGO, Margarida Lacombe. O pragmatismo no Supremo Tribunal Federal Brasileiro. Vinte anos da Constituição Federal de 1988. Rio de Janeiro: Lumen Juris, 2009.

CASA CIVIL DA PRESIDÊNCIA DA REPÚBLICA. Diretrizes gerais e guia orientativo para elaboração de Análise de Impacto Regulatório - AIR / Subchefia de Análise e Acompanhamento de Políticas Governamentais [et al.]. --Brasília: Presidência da República, 2018. Disponível em: <https://www.gov.br/casacivil/pt-

br/assuntos/governanca/regulacao/apresentacao-regulacao-pasta/comite-interministerial-degovernanca-aprova-as-diretrizes-gerais-e-roteiro-analitico-sugerido-para-analise-de-impactoregulatorio-diretrizes-air-e-o-guia-orientativo-para-elaboracao-de-analise-de-impactoregulatorio-guia-air/diretrizes_guia_air_cig_11junho2018.pdf>. Acesso em: 10.05.2020.

DAVID, Rene. Os grandes sistemas do Direito contemporâneo. 2. ed. Lisboa: Meridiano, 1978. 
EISENBERG, Jose. Pragmatismo jurídico. BARRETO, Vicente de Paulo (coord.).

Dicionário de Filosofia do Direito. São Leopoldo/Rio de Janeiro: Unisinos/Renovar, 2006.

JACOBS, Scott H. An Overview of Regulatory Impact Analysis in OECD Countries. OECD. Regulatory Impact Analysis: Best Practices in OECD Countries, 1997, p. 13-30. Disponível em: <http://www.oecd.org/dataoecd/21/59/35258828.pdf>. Acesso em: 10.05.2020.

MENAND, Louis. The Metaphysical Club. Nova York: Farrar, Straus and Giroux, 2001.

MENDONÇA, José Vicente Santos de. Direito constitucional econômico: a intervenção do Estado na economia à luz da razão pública e do pragmatismo. Belo Horizonte: Fórum, 2014. . Análise de Impacto Regulatório: o novo capítulo das agências reguladoras.

Revista Justiça e Cidadania, Rio de Janeiro, p. 30-34, 15 set. 2010.

MOREIRA NETO, Diogo de Figueiredo. Quatro paradigmas do Direito Administrativo Pós-Moderno. Belo Horizonte: Forum, 2008.

OECD. Introductory Handbook for Undertaking Regulatory Impact Analysis (RIA), p. 1-27, out. 2008. Disponível em: 〈http://www.oecd.org/dataoecd/48/14/44789472.pdf〉. Acesso em: 10.05.2020.

OLIVEIRA, Rafael Carvalho Rezende. Novo perfil da regulação estatal: Administração Pública de resultados e análise de impacto regulatório, Rio de Janeiro: Forense, 2015.

. Precedentes no Direito Administrativo, Rio de Janeiro: Forense, 2018.

Governança e Análise de Impacto Regulatório. Revista de Direito Público da

Economia, v. 36, p. 173-203, 2011 a.

A releitura do Direito Administrativo à luz do pragmatismo jurídico. Revista de Direito Administrativo, v. 256, p. 129-163, 2011 b.

POGREBINSCHI, Thamy. Pragmatismo: teoria social e política. Rio de Janeiro: Relume Dumará, 2005.

POSNER, Richard A. Law, Pragmatism and Democracy. Cambridge: Harvard University Press, 2005.

ROSE-ACKERMAN, Susan. Rethinking The Progressive Agenda: the Reform of Regulatory State. Nova York: The Free Press, 1992.

SALGADO, Lucia Helena; BORGES, Eduardo Bizzo de Pinho. Análise de impacto regulatório: uma abordagem exploratória, Brasília: Ipea, 2010.

SORRENTINO, Giancarlo. Diritti e partecipazione nell'amministrazione di resultato. Napoli: Editoriale Scientifica, 2003. 
SOUZA NETO, Cláudio Pereira de. Verticalização, cláusula de barreira e pluralismo político: uma crítica consequencialista à decisão do STF na ADIN 3685. Interesse Público, Porto Alegre, v. 37, 2006.

SPASIANO, Mario R. Funzione amministrativa e legalità di resultado. Torino: Giappichelli, 2003.

WEATHERILL, Stephen. The Challenge of Better Regulation. WEATHERILL, Stephen (org.). Better Regulation. Oxford: Hart, 2007.

Trabalho recebido em 05 de fevereiro de 2021

Aceito em 25 de março de 2021 